Original Research Paper

\title{
Association Study between Different Anthropometric Measures and other Clinical Markers in Saudi Female Students at King Abdulaziz University
}

\author{
${ }^{1}$ Asmaa H Almalki, ${ }^{2}$ Maha ST Saad, ${ }^{2}$ Shahad S Alzahrani, \\ ${ }^{2}$ Munira A Moalim, ${ }^{2}$ Safa OA Nahdi, ${ }^{2}$ Hala S Sonbol and ${ }^{1}$ Alana H Sunbol \\ ${ }^{1}$ Faculty of Medicine, King Abdulaziz Hospital, Jeddah, Kingdom of Saudi Arabia \\ ${ }^{2}$ Department of Biochemistry, Faculty of Sciences, King Abdulaziz University, Jeddah, Kingdom of Saudi Arabia
}

\author{
Article history \\ Received: 20-05-2019 \\ Revised: 14-07-2019 \\ Accepted: 15-01-2020 \\ Corresponding Author: \\ Hala Salim Sonbol \\ Department of Biochemistry, \\ Faculty of Science, King \\ Abdulaziz University, P.O. Box \\ No. 122522, Jeddah, 21332, \\ Kingdom of Saudi Arabia \\ Tel: 00966500599560 \\ Fax: 00966126679521 ext. 110 \\ E-mail: hsunbol@kau.edu.sa
}

\begin{abstract}
This research addresses nutritional status, Body Mass Index (BMI), Waist-Hip Ratio (WHR), physical activity and Blood Pressure (BP) among female students attending King Abdul-Aziz University (KAU) and correlates the changes in BMI and WHR with Systolic Blood Pressure (SBP) and diastolic blood pressure (DBP). Saudi female students $(\mathrm{N}=232)$ aged 18 to 27 years old were recruited over two academic semesters. The students were selected randomly. Socio-demographic information and lifestyle data were collected using a self-administered questionnaire. BP is measured using a validated sphygmomanometer and BMI was calculated. The WHR was calculated after measuring waist circumference and hip circumference using a measuring tape. Fasting Blood Glucose (FBG) was tested using a glucometer. Of all the students, according to BMI, $20.70 \%$ were underweight, $59.90 \%$ were normal, $11.50 \%$ were overweight and $7.80 \%$ were obese. While, according to WHR, 96.60\% had a normal weight and $2.20 \%$ were overweight. In addition, $0.90 \%$ had dyslipidemia and $61.60 \%$ performed physical activity on a regular basis. Family history was positive for diabetes mellitus in $86.60 \%$ and heart diseases in $47.80 \%$. SBP was decreased by $4.70 \%$ while DBP was decreased by $24.10 \%$. Among all participants, there were significant positive correlations between $\mathrm{SBP}$ and DBP and BMI; between DBP and BMI and WHR; between BMI and age and WHR. A high prevalence of hypotension was detected among female students that may have been due to bad eating habits and intermittent physical activity. Regular health checkups should be done to avoid chronic diseases and cardiovascular complications. Further studies should be performed to promote the importance of lifestyle modifications.
\end{abstract}

Keywords: Body Mass Index, Diastolic Blood Pressure, Physical Activity, Systolic Blood Pressure, Waist-Hip Ratio

\section{Introduction}

Identifying the health and healthcare needs of the next generation requires the examination of the health status of young people (Patton et al., 2012). It is vital to monitor the health status of younger generations as they may face many risks at a young age (Catalano et al., 2012). The up-to-date median age in the Kingdom of Saudi Arabia (KSA) is 27.5 years of age with a life expectancy of 75.5 years of age (http://worldpopulationreview.com). Due to the high percentage of the young population in KSA, there is an increased risk of different diseases, mental illness and behavioural disorders (Memish et al., 2014). The nutrition transition with associated lifestyle-related noncommunicable diseases has rapidly reached many developing countries, including KSA (Memish et al., 2014). Many case studies discussed how obesity may lead 
to development of different diseases, especially cardiovascular diseases (Abalkhail, 2000; Al-Daghri et al., 2010; El Mouzan et al., 2010).

One of the risk factors that affects both the young and elderly age groups is Blood Pressure (BP). BP is the pressure of the resistance of blood flow against arterial walls (Martin, 2015). Systolic Blood Pressure (SBP) refers to the amount of pressure in arteries during the contraction of heart ventricular muscles. Diastolic Blood Pressure (DBP) is the pressure required to allow a constant flow of blood in the blood vessels (Sizer et al., 1991). BP increases progressively with age in both males and females due to many factors such as changes in the resistance in the blood vessels as well as changes in the cardiac output (Al-Salloum et al., 2009). The definition of hypotension varied among authors over the years, making it difficult to estimate its incidence. The reported incidences of hypotension ranged between $1.9 \%$ and $71 \%$ (Ngan Kee et al., 2005). More studies defined hypotension as proportional reduction of SBP to a value lower than $70 \%-80 \%$ of baseline, or a reduction of the SBP value under $90 \mathrm{~mm}$ $\mathrm{Hg}$ and DBP below $60 \mathrm{mmHg}$ in adults and that differ according to age, BMI and gender (Liu et al., 2015). Physical activity was associated with a decrease in BP when compared to pre-exercise resting values; this phenomenon is called Post-Exercise Hypotension (PEH) (Barreto et al., 2015). Post-exercise decrease in BP mainly occurs in hypertensive individuals (Polito and Farinatti, 2006), which substantiates the medical recommendation of physical exercise as a nonpharmacological strategy to control and prevent Arterial Hypertension (AH) (Senna et al., 2016).

A predictor of change in health risk is Body Mass Index (BMI). It is a measure of the human body weight to height (Sizer et al., 2012). The World Health Organization (WHO) classifies BMI as underweight $\left(<18 \mathrm{~kg} / \mathrm{m}^{2}\right)$, normal $\left(18.5-24.9 \mathrm{~kg} / \mathrm{m}^{2}\right)$, overweight $(25$ $\left.29.90 \mathrm{~kg} / \mathrm{m}^{2}\right)$ and obese $\left(\geq 30 \mathrm{~kg} / \mathrm{m}^{2}\right)$ (Gibson, 2005). The addition of Waist Circumference (WC) to BMI predicts a greater variance in health risk than BMI does alone. In women, BMI was associated with an increased risk of many diseases; however, Waist-Hip Ratio (WHR) appeared to be a stronger independent risk factor than BMI (Lapidus et al., 1984). Epidemiological studies showed a positive correlation between BMI and BP (Saxon et al., 2010).

Chronic diseases, such as Chronic Vascular Disease (CVD) are rising dramatically in the Eastern Mediterranean region. About $45 \%$ of the region's disease burden is due to non-communicable diseases and it is expected that this burden will rise to $60 \%$ by the year 2020 (Koura et al., 2012). The direct positive relationship between BP and cardiovascular risk was found to be strong, continuous, graded, consistent, independent, predictive and etiologically significant for those with and without coronary heart disease (NIH, 2002). An increase in WC, WHR and BMI are also strong predictors of Type 2 Diabetes Mellitus (T2DM) (Vazquez et al., 2007). Additional factors that affect BP include smoking. It has been suggested that long-term cigarette smoking raises BP by causing an increase in inflammation, endothelial dysfunction, plaque progression and vascular damage. An increase in BP and the development of hypertension in cigarette smokers compared to non-smokers has been reported in some studies (Halimi et al., 2002; Bowman et al., 2007). Other studies, however, have reported that smoking cigarettes reduces the prevalence of hypertension and lowers BP by $55 \%$ in non-smokers, $33 \%$ in ex-smokers and $15 \%$ in smokers (Gumus et al., 2013). Also, previous studies have reported that smoking causes T2DM (Oh et al., 2005; Jee et al., 2010).

This study aimed to find an association between BMI, BP, nutritional status and lifestyle of female students attending King Abdul-Aziz University (KAU) in the Western region of the Kingdom of Saudi Arabia (KSA). With the increasing burden of non-communicable disease, studying the lifestyle and wellbeing of young people could be an indicator of upcoming health and healthcare requirements of the next generation. In addition, it promotes leading healthier lives.

\section{Materials and Methods}

\section{Subject Selection and Recruitment}

This cross-sectional study was conducted at the Faculty of Science, KAU, Jeddah, KSA (Western Region). Two hundred and thirty-two female students aged 18 to 27 years old were recruited over two academic semesters in 2018. Students were selected randomly. The exclusion criteria were participants with a history of diabetes mellitus, hypertension, heart diseases, kidney diseases, polycystic ovary syndrome, Acquired Immune Deficiency Syndrome (AIDS), thyroid diseases, liver diseases, neurological diseases, such as epilepsy, rheumatoid arthritis, depression, and subjects who were taking medications including antibiotics, hormonal drugs, or were on immunotherapy. Pregnant and lactating women were also excluded. The students signed informed consent at the beginning of the study. The Research Ethics Committee, Unit of Biomedical Ethics, KAU, Jeddah, KSA approved the experimental protocol.

\section{Anthropometric Measurements}

Socio-demographic information such as age, phone number, family history, risk factors for CVD (e.g. 
smoking and dyslipidemia) and other lifestyle data was collected using a self-administered questionnaire.

Standing height $(\mathrm{cm})$ and weight $(\mathrm{kg})$ were measured in light clothing, without shoes, using the ACTEST medical $160200 \mathrm{~kg}$ body weight -height scale (China). BMI was calculated as weight $(\mathrm{kg}) /$ height $\left(\mathrm{m}^{2}\right)$. Normal weight is defined as a BMI between $18.5-24.99 \mathrm{~kg} / \mathrm{m}^{2}$, underweight as $<18.5 \mathrm{~kg} / \mathrm{m}^{2}$, overweight as BMI $\geq 25$ $<30 \mathrm{~kg} / \mathrm{m}^{2}$ and obese as BMI $\geq 30 \mathrm{~kg} / \mathrm{m}^{2}$ according to the International Obesity Classification (www.WHO.com). Waist to hip ratio was estimated and the subjects were categorized as normal $(<0.80)$; overweight $(0.80-0.84)$ and obese $(\geq 0.80)$. Physically active students were classified according to whether they did 1-2 $\mathrm{h}$ of exercise or if they walked for two hours per day.

$\mathrm{BP}$ was measured in the seated position using a British Hypertension Society validated BP monitor, with appropriate cuff size and interface (OMRON, Japan). Large, medium and small cuffs were used according to the patient's arm circumference. The subjects were not using their mobile phones; they did not cross their legs, or talk during the BP measurement. After resting for $5 \mathrm{~min}$, the pressure cuff was applied closely to the upper arm. The cuff was inflated with air to pressure above the level at which the radial pulse could no longer be felt. Then the stethoscope was put over the brachial artery and the mercury column was allowed to decrease at the rate of $2 \mathrm{mmHg} / \mathrm{second}$. The first perception of the sound was taken as the systolic pressure and then the mercury was allowed to fall further until the sound finally disappeared. The level where sound disappeared was taken as DBP. The cuff was then deflated to zero pressure. BP was measured three times with a rest interval for 5 min using the left arm supported at heart level. Subjects were classified as having normal BP (SBP 90- $<120 \mathrm{~mm} \mathrm{Hg}$ and DBP 60$<80 \mathrm{~mm} \mathrm{Hg}$ ), prehypertension (SBP 120-139 mm Hg and/or DBP 80-89 $\mathrm{mm} \mathrm{Hg}$ ), or hypertension (SBP > $140 \mathrm{~mm} \mathrm{Hg}$ and DBP $>90 \mathrm{~mm} \mathrm{Hg}$ ) according to the definitions of the Joint National Committee 7 (JNC7) (http://worldpopulationreview.com). Blood glucose was measured twice using (ACCU-CHEK Performa 2015 Roche Diabetes Care $\mathrm{GmbH})$.

\section{Statistical Analysis}

Statistical analyses were performed using the Statistical Package for Social Science package (version 20, SPSS INC., Chicago, Illinois, USA). Descriptive data were given as mean +/- standard deviation (minimum-maximum) or number $(\%)$ as appropriate. The chi-square test was used to compare hypotensive and normotensive participants. The comparison of variables before and after meals was performed by using the paired student " $\mathrm{t}$ " test. Correlations between parametric parameters were made using Pearson's correlation. A $P$ value of $\leq 0.05$ was considered significant.

\section{Results}

\section{General Characteristics}

This study included 232 female participants between the ages of 18 and 27 years old. The demographic characteristics and parameters of the study group are presented in Table 1. The average BMI was normal, comprising of $59.90 \%$ of participants; $20.70 \%$ of were underweight, $11.50 \%$ were overweight and $7.80 \%$ were classified as obese. The waist-hip ratio was mostly normal (96.60\%); only $2.20 \%$ were overweight and $1.3 \%$ were obese. Regarding BP, $95.30 \%$ had a normal SBP and $4.7 \%$ were hypotensive. Also, $75.90 \%$ had a normal DBP and $24.10 \%$ were hypotensive. Furthermore, $47.80 \%$ of the participants had a family history of heart diseases and $86.60 \%$ had a family history of diabetes mellitus. Fasting blood glucose was normal in all participants. Lifestyle habits of the participants were recorded. $90.90 \%$ never smoked, $6.50 \%$ were smokers and $2.60 \%$ formerly smoked. Regarding diet and exercise, $61.6 \%$ performed a type of physical activity as part of their usual routines and $4.70 \%$ were on a diet.

\section{BP Pressure Correlations}

Arterial blood pressure status was cross-tabulated with BMI, WHR, FBG, physical activity and smoking (Table 2). Out of the 232 participants, 56 were found to be hypotensive, with either a low SBP, DBP, or both; and 176 had normal BPs. Participants who were underweight $(25.00 \%)$ and those with a normal BMI $(64.30 \%)$ were mostly hypotensive. Participants who were overweight $(13.10 \%)$ and obese $(9.10 \%)$ had normal BPs. There was no statistical significance between the two variables. Regarding WHR, participants who were within the normal range were mostly hypotensive $(98.20 \%)$ and those who were overweight and obese had normal BPs $(2.30 \%$ and $1.70 \%$ respectively). Most of the participants with comorbidities such as dyslipidemia were hypotensive $(1.80 \%)$ and those who were on a diet had normal BPs $(5.10 \%) .64 .30 \%$ of participants who performed regular physical activity were hypotensive. Furthermore, the majority of smokers had normal BPs (7.40\%). Former smokers and non-smokers $(5.40 \%$ and $91.10 \%$ respectively) however, were mostly hypotensive. There is no statistical significance between the previous variables. There was a statistical significance (0.026) between participants with a family history of heart disease and BP, most of which had normal BPs $(51.70 \%)$. however the family history of diabetes mellitus showed no significance. The majority had normal BPs $(86.90 \%)$. 
Table 1: Demographic and characteristics of participants

\begin{tabular}{|c|c|}
\hline Characteristics & Value \\
\hline$\overline{\text { Age (years) }}$ & $20.98 \pm 1.48(18.00-27.00)$ \\
\hline Weight (Kg) & $53.67 \pm 13.41(31.00-108.00)$ \\
\hline Height (meter) & $1.57 \pm 0.06(1.43-1.77)$ \\
\hline $\operatorname{BMI}\left(\mathrm{kg} / \mathrm{m}^{2}\right)$ & $21.63 \pm 5.09(13.87-43.77)$ \\
\hline \multicolumn{2}{|l|}{ Category BMI } \\
\hline Underweight $\left(<18.50 \mathrm{~kg} / \mathrm{m}^{2}\right)$ & $48(20.70 \%)$ \\
\hline $\operatorname{normal}\left(18.5-24.9 \mathrm{~kg} / \mathrm{m}^{2}\right)$ & $139(59.90 \%)$ \\
\hline Overweight $\left(25-29.90 \mathrm{~kg} / \mathrm{m}^{2}\right)$ & $27(11.50 \%)$ \\
\hline Obesity $\left(\geq 30 \mathrm{~kg} / \mathrm{m}^{2}\right)$ & $18(7.80 \%)$ \\
\hline Waist (cm) & $25.66 \pm 4.16(12.00-48.00)$ \\
\hline Hip $(\mathrm{cm})$ & $37.41 \pm 4.21(30.00-53.00)$ \\
\hline WHR ratio & $0.68 \pm 0.06(0.38-0.96)$ \\
\hline \multicolumn{2}{|l|}{ WHR ratio category } \\
\hline $\operatorname{Normal}(<0.80)$ & $224(96.60 \%)$ \\
\hline Overweight $(0.80-0.84)$ & $5(2.20 \%)$ \\
\hline Obesity $(\geq 0.80)$ & $3(1.30 \%)$ \\
\hline \multicolumn{2}{|l|}{ Morbidities and habits } \\
\hline Dyslipidemia & $2(0.90 \%)$ \\
\hline On a diet & $11(4.70 \%)$ \\
\hline Perform physical activity & $143(61.60 \%)$ \\
\hline \multicolumn{2}{|l|}{ Smoking } \\
\hline Current & $15(6.50 \%)$ \\
\hline Formed & $6(2.60 \%)$ \\
\hline Never & $211(90.90 \%)$ \\
\hline Family history of diabetes mellitus & $201(86.60 \%)$ \\
\hline Family history of heart diseases & $111(47.80 \%)$ \\
\hline $\mathrm{SBP}(\mathrm{mmHg})$ & $101.50 \pm 7.71(80.00-124.00)$ \\
\hline \multicolumn{2}{|l|}{ Category of systolic blood pressure } \\
\hline Hypotension $(<90 \mathrm{mmHg})$ & $11(4.70 \%)$ \\
\hline Normal (120 - 139 mm Hg) & $221(95.30 \%)$ \\
\hline Diastolic blood pressure $(\mathrm{mmHg})$ & $63.78 \pm 6.26(49.00-83.00)$ \\
\hline \multicolumn{2}{|l|}{ Category of DBP } \\
\hline Hypotension $(<60 \mathrm{mmHg})$ & $56(24.10 \%)$ \\
\hline Normal $(60-89 \mathrm{~mm} \mathrm{Hg})$ & $176(75.90 \%)$ \\
\hline Pulse pressure (mmHg) & $74.41 \pm 9.58(36.00-108.00)$ \\
\hline $\mathrm{FBG}(\mathrm{mg} / \mathrm{dl})$ & $88.42 \pm 8.41(70.00-122.00)$ \\
\hline
\end{tabular}

Table 2: Cross tabulation between clinical characteristics and hypotension in Saudi female students

\begin{tabular}{|c|c|c|c|}
\hline Characteristics & Hypotension $(n=56)$ & Normal $(n=176)$ & Significance changes \\
\hline Category BMI & & & 0.278 \\
\hline Underweight $\left(<18.50 \mathrm{~kg} / \mathrm{m}^{2}\right)$ & $14(25.00 \%)$ & $34(19.30 \%)$ & \\
\hline normal $\left(18.5-24.9 \mathrm{~kg} / \mathrm{m}^{2}\right)$ & $36(64.30 \%)$ & $103(58.30 \%)$ & \\
\hline Overweight $\left(25-29.90 \mathrm{~kg} / \mathrm{m}^{2}\right)$ & $4(7.10 \%)$ & $23(13.10 \%)$ & \\
\hline Obesity $\left(\geq 30 \mathrm{~kg} / \mathrm{m}^{2}\right)$ & $2(3.60 \%)$ & $16(9.10 \%)$ & \\
\hline WHR category & & & 0.600 \\
\hline $\operatorname{Normal}(<0.80)$ & $55(98.20 \%)$ & $168(96.00 \%)$ & \\
\hline Overweight $(0.80-0.84)$ & $1(1.80 \%)$ & $4(2.30 \%)$ & \\
\hline Obesity $(\geq 0.80)$ & - & $3(1.70 \%)$ & \\
\hline Morbidities and habits & & & \\
\hline Dyslipidemia & $1(1.80 \%)$ & $1(0.60 \%)$ & 0.220 \\
\hline On a diet & $2(3.60 \%)$ & $9(5.10 \%)$ & 0.479 \\
\hline Perform physical activity & $36(64.30 \%)$ & $107(60.80 \%)$ & 0.381 \\
\hline Smoking & & & 0.207 \\
\hline Current & $2(3.60 \%)$ & $13(7.40 \%)$ & \\
\hline Formed & $3(5.40 \%)$ & $3(1.70 \%)$ & \\
\hline Never & $51(91.10 \%)$ & $160(90.90 \%)$ & \\
\hline Family history of diabetes mellitus & $48(85.70 \%)$ & $153(86.90 \%)$ & 0.485 \\
\hline Family history of heart diseases & $20(35.70 \%)$ & $91(51.70 \%)$ & 0.026 \\
\hline
\end{tabular}

Data are expressed as number (\%). Significance between hypotensive and normotensive was made using the Chi-Square test. WHR: Waist-Hip Ratio; SBP: Systolic Blood Pressure; DBP: Diastolic Blood Pressure 
Table 3: Correlations coefficient between different parameters in in Saudi female students

\begin{tabular}{llllll}
\hline Parameters & SBP & DBP & Age & BMI & WHR \\
\hline DBP & $0.742(0.0001)$ & - & - & - & - \\
Age & $-0.054(0.415)$ & $0.002(0.978)$ & - & - & - \\
BMI & $0.201(0.002)$ & $0.176(0.007)$ & $0.130(0.048)$ & - & - \\
WHR & $0.107(0.103)$ & $0.137(0.037)$ & $0.000(0.996)$ & $0.438(0.0001)$ & - \\
FBG & $0.107(0.105)$ & $0.091(0.167)$ & $0.066(0.318)$ & $0.116(0.078)$ & $0.108(0.100)$ \\
\hline
\end{tabular}

Data are expressed as correlation coefficient $(\mathrm{r})$ and significance $(\mathrm{P})$. Significance between parameters was made using Person correlations. WHR: Waist-Hip Ratio; SBP: Systolic Blood Pressure; DBP: Diastolic Blood Pressure; FBG: Fasting Blood Glucos

\section{Correlation between Demographic Characteristics and $B P$}

The correlation between BP, BMI, WHR and FBG is shown in Table 3. SBP was positively correlated with DBP $(r=0.742, P=0.0001)$. Furthermore, BMI was positively correlated with SBP $(\mathrm{r}=0.201, \mathrm{P}=0.002)$, DBP $(r=0.176, P=0.007)$, age $(r=0.130, P=0.048)$ and WHR $(\mathrm{r}=0.438, \mathrm{P}=0.0001)$. DBP also has a positive correlation with WHR $(r=0.137, \mathrm{P}=0.037)$.

\section{Discussion}

This cross-sectional study showes the relationship between different anthropometric parameters in a group of healthy Saudi female students attending King AbdulAziz University, Jeddah, Saudi Arabia. Factors including BMI, WHR, nutritional status, physical activity, BP, dietary habits, smoking and family history of diseases were assessed. Body mass index is considered to be one of the best indicators of nutritional status in adults (Kapoor et al., 2010). In this study, most of the participants were found to have a normal BMI (59.90\%), while $20.70 \%$ were underweight, $11.50 \%$ were overweight and $7.80 \%$ were obese. Meanwhile, in terms of WHR, most of the participants were normal $96.60 \%$; while $2.20 \%$ were overweight and $1.30 \%$ were obese. Straying from the normal ranges of body weight can cause health problems. The results of this study showed significant positive correlations between BMI and SBP, DBP, WHR and age as well as between WHR and DBP. The positive correlation between BMI and waist circumference was observed in previous studies (Ford et al., 2003; Sunitha and Satyanarayana, 2012; Chen et al., 2019). An increase in WHR is a good indicator of central obesity. An increase in BMI and WHR are risk factors of hypertension (Sasi and Devi, 2017). Positive correlations between BMI, WHR and BP were reported in a cross sectional study to assess anthropometric measures in medical and dental students in the University of Jaipur (Pathak et al., 2018). Significant positive associations between BMI and BP were also reported in the Indian population (Tandon, 2006; Mungreiphy et al., 2011).

A British study conducted by Han et al showed that participants with hypertension had higher body fat and lower skeletal muscle mass than patients with normal BPs in both men and women. Thus, these two parameters should also be considered when looking at the correlation between different anthropometric measures and BP (Han et al., 2018).

Obesity is a risk factor for the development of dyslipidemia, Type 2 diabetes mellitus and insulin resistance which can lead to cardiovascular diseases and hypertension due to the alteration of vascular functions (Kotsis et al., 2010; Bastien et al., 2014; Awasthi et al., 2017). Obesity has been shown to contribute to the dysregulation of blood pressure both directly and indirectly. The former through its effect on adipokines on the vessels and the latter by affecting other body systems' regulation of blood pressure (Balistreri et al., 2010). An example of this is through vascular dysfunction and thickening of the vascular smooth muscle layer that occurs due to alterations in endothelial function. This occurs with obesity when there is increased expression of pro-inflammatory adipokines such as tumor necrosis factor- $\alpha$ (TNF- $\alpha$ ); leading to changes in the vessel wall, causing different pathologies (Balistreri et al., 2010).

Atherosclerosis is the major cause of morbidities and mortalities worldwide (Rafieian-Kopaei et al., 2014). It is a condition caused by fat deposition in the inner layer of arteries which causes the formation of atheromatous plaques. These plaques accumulate with time, affecting the blood flow in the arteries. There are several genetic as well as environmental factors that contribute to the progression of atherosclerosis. A few of these risk factors include diabetes, dyslipidemia, smoking and hypertension (Singh et al., 2002). Atherosclerosis isone of the leading causes of cardiovascular diseases (Torres et al., 2015). Leading a healthier lifestyle by avoiding smoking, eating healthier and exercising regularly can help prevent many of the risk factors for atherosclerosis and thus preventing its complications. By assessing the different anthropometric measures mentioned in this study, we can look at the overall health profile of the students to see if they have any of the previously mentioned risk factors. This would be an important step in preventing cardiovascular diseases.

In this study, $86.60 \%$ of the participants had a family history of DM and $47.80 \%$ had positive family history of 
heart diseases. Regarding BP, 56 (24.10\%) of participants were found to be hypotensive and 176 (75.90\%) had normal BPs. However, there was no significant correlation between family history of DM or fasting blood sugar levels and the studied anthropometric measurements. In this respect, Bianco et al. (2013) reported that people who have high BMIs, or a positive family history of DM and myocardial infarctions (MIs) have a higher risk of developing T2DM or MIs later on in life compared to those with lower BMI and no family history of T2DM or a history of MIs. Another study also associated BMI, WC and WHR with T2DM (Vazquez et al., 2007). Prevention of diabetes mellitus and cardiovascular events such MIs needs motivation to modify unhealthy habits and thus lead a healthier lifestyle. This is crutial for avoiding such diseases.

In this study $24.14 \%$ of the participants were hypotensive. The cause of hypotension in the females involved in this study was not clear. As mentioned previously, lifestyle changes along with dietary modifications, will reduce the risk of cardiovascular diseases caused by risk factors such as hypertension and obesity. BP is affected by several factors such as BMI and physical activity (Abdalla et al., 2017). This study showed that $64.30 \%$ of the participants who performed regular physical activities were hypotensive and $60.80 \%$ had normal BPs. Another study also showed that intermittent bouts of physical activities lead to the reduction of $\mathrm{BP}$ in prehypertensive and hypertensive patients (Park et al., 2008).

\section{Conclusion}

We conclude that Saudi female students between the ages of 18-27 years have a high prevalence of hypotension that could be contributed to unhealthy diets with low nutritional benefits, performing intermittent physical activity and high family history of heart diseases $(35.70 \%)$ among hypotensive students. This study also showes that BMI is closely associated with both systolic and DBP. Thus, encouraging healthy eating, promoting regular physical activity and monitoring changes in $\mathrm{BP}$ should be something that is focused on in people of this age group.

There were several limitations of this study. Firstly, it was difficult to enroll volunteers due to the students' different class schedules. Secondly, the survey did not contain the total intake (Kcal/d), dietary type and psychosocial issues such as stress or depression, which could have affected the participants' BMI and BP. Clinical research should attempt to develop more detailed diagnostic as well as analytical measures to assess both quantitatively and qualitatively the body weight disturbance and abnormal eating patterns of adolescent and young adult population.

\section{Acknowledgement}

This work was supported by KAU Endowment (WAQF) and the Science Research and Innovation Unit in Faculty of Science, King Abdul-Aziz University, Jeddah, Saudi Arabia.

\section{Author's Contributions}

Asmaa Almalki, Maha Saad, Shahad Alzahrani, Munira Moalim and Safa Nahdi: Performed the experiment and were involved in the design of the study, data collection and analysis and contributed to the planning and writing the article.

Hala Sonbol: Supervised the research and provided the equipment and space to perform the experiment. Was involved in the design of the study, data analysis and interpretation, as well as writing, editing and the final review of the article.

Alana Sunbol: Was involved in data interpretation, as well as writing, editing and the final review of the article.

\section{Ethics}

This article is original and contains unpublished material. The corresponding author confirms that all of the other authors have read and approved the manuscript and no ethical issues involved.

\section{References}

Abalkhail, B., 2000. Overweight and obesity among Saudi Arabian children and adolescents between 1994 and 2000. East Mediterr Health J., 8: 470-9. PMID: 15603027

Abdalla, M.S., I.A. Ali and O.A. Musa, 2017. Correlation between body mass index and blood pressure. Int. J. Scientific Res. Public., 7: 127-130.

Al-Daghri, N., M. Alokail and S. Kumar, 2010. Establishing abdominal height cut-offs and their association with conventional indices of obesity among Arab children and adolescents.ASM J., 30: 209-214.

Al-Salloum, A.A., M.I. El Mouzan, A.S. Al Herbish, A.A. Al Omar and M.M. Qurashi, 2009. Blood pressure standards for Saudi children and adolescents.ASM J., 29: 173-178.

Awasthi, A., C.R. Rao, D.S. Hegde and N.K. Rao, 2017. Association between type 2 diabetes mellitus and anthropometric measurements - a case control study in South India. J. Prev. Med. Hyg., 58: 56-62. PMID: 28515633

Balistreri, C.R., C. Caruso and G. Candore, 2010. The role of adipose tissue and adipokines in obesityrelated inflammatory diseases. Mediators Inflammat., 2010: 802078-802078.

DOI: $10.1155 / 2010 / 802078$ 
Barreto, C.B., S.D.S. Aguiar, R. Palmeira, H.J.C. Junior and E.M.L. Gargaglione et al., 2015. What is the minimum volume of aerobic physical exercise necessary to elicit postexercise hypotension? J. Exercise Physiologyonline, 18: 1-12.

Bastien, M., P. Poirier, I. Lemieux and J.P. Després, 2014. Overview of epidemiology and contribution of obesity to cardiovascular disease. Progress Cardiovascular Diseases J., 56: 369-381.

Bianco, A., F. Pomara and A. Palma, 2013. Type 2 diabetes family histories, body composition and fasting glucose levels: A cross-section analysis in healthy sedentary male and female. Iranian J. Public Health, 42: 681-690. PMID: 24427747

Bowman, T.S., J.M. Gaziano, J E. Buring and H.D. Sesso, 2007. A prospective study of cigarette smoking and risk of incident hypertension in women. J. Am. College Cardiology, 50: 2085-2092.

Catalano, R.F., A.A. Fagan, L.E. Gavin and M.T. Greenberg, 2012. Worldwide application of prevention science in adolescent health. Lancet, 379: 1653-1664.

Chen, Y., Y. Yang, H. Jiang, X. Liang and Y. Wang et al., 2019. Associations of BMI and waist circumference with all-cause mortality: A 22-year cohort study. Obesity Society J., 27: 662-669.

El Mouzan, M.I., P.J. Foster, A.S. Al Herbish, A.A. Al Salloum and A.A. Al Omer et al., 2010. Prevalence of overweight and obesity in Saudi children and adolescents. ASM J., 30: 203-208.

Ford, E.S., A.H. Mokdad and W.H. Giles, 2003. Trends in waist circumference among U.S. adults. Obes Res., 11: 1223-1231. DOI: 10.1038/oby.2003.168

Gibson, R.S., 2005. Principles of Nutritional Assessment. 1st Edn., Oxford University Press, Oxford, ISBN-10: 0195171691, pp: 908.

Gumus, A., S. Kayhan, H. Cinarka and U. Sahin, 2013. The effect of cigarette smoking on blood pressure and hypertension. Advances Biosci. Clinical Med. J., 1: 6-8. DOI: 10.7575/aiac.abcmed.v.1n.1p.6

Han, T.S., Y.Y. Al-Gindan, L. Govan, C.R. Hankey and M.E.J. Lean, 2018. Associations of body fat and skeletal muscle with hypertension. J. Clin. Hypertens, 21: 230-238.

Halimi, J.M., B. Giraudeau, S. Vol, E. Cacès and H. Nivet, 2002. The risk of hypertension in men: direct and indirect effects of chronic smoking. J. Hypertens., 20: 187-193. PMID: 11821702

http://worldpopulationreview.com

Jee, S.H., A.W. Foong, N.W. Hur and J.M. Samet, 2010. Smoking and risk for diabetes incidence and mortality in Korean men and women. Diabetes Care, 33: 2567-2572. DOI: $10.2337 / \mathrm{dc} 10-0261$
Kapoor, A.K., M. Dhall and R. Tyagi, 2010. Nutritional Status and Ageing among Car Nicobarese and Nolia Males of India. Open Anthropology J., 3: 155-160.

Kotsis, V., S. Stabouli, S. Papakatsika, Z. Rizos and G. Parati, 2010. Mechanisms of obesity-induced hypertension. Hypertension Res. J., 33: 386-393.

Koura, M.R., B.K. Al Dabal, P. Rasheed, L.S. Al Sowielem and S.M. Makki, 2012. Prehypertension among young adult females in Dammam, Saudi Arabia. Eastern Mediterranean Health.

Lapidus, L., C. Bengtsson, B Larsson, K. Pennert and E. Rybo et al., 1984. Distribution of adipose tissue and risk of cardiovascular disease and death: A 12 year follow up of participants in the population study of women in Gothenburg, Sweden. Brit. Med. J., 289: 1257-1261.

DOI: $10.1136 / \mathrm{bmj} .289 .6454 .1257$

Liu, H., Y, Huang, M. Diao, H. Li and Y. Ma et al., 2015. Determination of the $90 \%$ Effective Dose (ED90) of phenylephrine for hypotension during elective cesarean delivery using a continual reassessment method. Eur. J. Obstet. Gynecol. Reprod. Biol., 194: 136-140.

DOI: 10.1016/j.ejogrb.2015.07.001

Martin, E., 2015. Concise Colour Medical Dictionary. 1st Edn., Oxford University Press, Oxford, UK, ISBN-10: 0199687994, pp: 880.

Memish, Z.A., S. Jaber, A.H. Mokdad, M.A. AlMazroa and C.J.L. Murray et al., 2014. Burden of disease, injuries and risk factors in the Kingdom of Saudi Arabia, 1990-2010. Prev. Chronic Dis., 11: E169- E169. DOI: 10.5888/pcd11.140176

Mungreiphy, N.K., S. Kapoor and R. Sinha, 2011. Blood pressure, waist to hip ratio and body mass index among affluent Punjabi girls of Delhi. Acta Medica Auxol., 32: 153-157.

Ngan Kee, W.D., K.S. Khaw and F.F. Ng, 2005. Prevention of hypotension during spinal anesthesia for cesarean delivery: An effective technique using combination phenylephrine infusion and crystalloid cohydration. Anesthesiology, 103: 744-750. DOI: $10.1097 / 01$. sa.0000234692.69247.01

NIH, 2002. Primary prevention of hypertension: Clinical and public health advisory from the national high blood pressure education program. US Department of Health and Human Service, National Institutes of Health, National Heart, Lung and Blood Institute, National High Pressure Education Program, NIH.

Oh, S.W., Y.S. Yoon, E.S. Lee, W.K. Kim and C. Park, et al., 2005. Association between cigarette smoking and metabolic syndrome. Diabetes Care, 28: 2064-2066. DOI: 10.2337/diacare.28.8.2064 
Park, S., L.D. Rink and J.P. Wallace, 2008. Accumulation of physical activity: Blood pressure reduction between 10-min walking sessions. J. Human Hypertension, 22: 475-482.

Pathak, R., B. Yadav, A.K. Sharma, A.K. Singh and S.K. Sharma et al., 2018. Cross sectional study of body mass index, waist hip ratio and blood pressure among medical and dental students. IJMSIR, 3: 159-166.

Patton, G., C. Coffey, C. Cappa, C. Currie and D. Riley et al., 2012. Health of the world's adolescents: A synthesis of internationally comparable data. Lancet, 379: 1665-1675. DOI: 10.1016/S0140-6736(12)60203-7

Polito, M.D. and P.T.V. Farinatti, 2006. Blood pressure behavior after counter-resistance exercises: A systematic review on determining variables and possible mechanisms. Revista Brasileira de Medicina do Esporte, 12: 386-392.

DOI: 10.1097/01.sa.0000234692.69247.01

Rafieian-Kopaei, M., M. Setorki, M. Doudi, A. Baradaran et al., 2014. Atherosclerosis: Process, indicators, risk factors and new hopes. Int. J. Prev. Med. Aug., 5: 927-946.

Sasi, R.S.K. and U.S. Devi, 2017. Assessment of body mass index, waist hip ratio, blood pressure, pulse pressure among obese male population. Sch. J. Applied Med. Sci., 5: 1832-36. DOI: $10.21276 /$ sjams

Saxon, S., M. Etten and E. Perkins, 2010. The Nervous System. In: A Guide for the Helping Professions: Physical Change and Aging, Springer, New York.
Senna, G., C. Queiroz De Oliveira, S. Kreuger, E. Scudese and W. Monteiro et al., 2016. Hypotensive effect of resistance training performed on stable vs. unstable surfaces. J. Exercise Physiol. Online, 19: 17-26.

Singh, R.B., S.A. Mengi, Y.J. Xu, A.S. Arneja and N.S. Dhalla, 2002. Pathogenesis of atherosclerosis: A multifactorial process. Exp. Clin. Cardiol., 7: 40-53. PMID: 19644578

Sizer, F.S., L.A. Piché, E.N. Whitney and E. Whitney, 2012. Nutrition: Concepts and controversies. Cengage Learning, Toronto Canada.

Sizer, F.S., L.A. Piché, E.N. Whitney and E Whitney, 1991. Conditions of the Prostate. In: The Lippincott Manual of Nursing Practice, Brunner, L.S. and D.S. Suddarth (Eds.), JB Lippincott Co., Philadelphia.

Sunitha, P. and N. Satyanarayana, 2012. Correlation of anthropometric parameters on blood pressure in normotensive males. IOSR J. Pharmacy, 2: 593-598.

Tandon, K., 2006. Obesity, its distribution pattern and health implications among Khatri population.

Torres, N., M. G-Cruz, L.A. V-Villegas and A.R. Tovar, 2015. Nutrition and atherosclerosis. Arch. Med. Res. J., 46: 408-426.

DOI: $10.1016 /$ j.arcmed.2015.05.010

Vazquez, G., S. Duval, D.R. Jacobs and K. Silventoinen Jr., 2007. Comparison of body mass index, waist circumference and waist/hip ratio in predicting incident diabetes: A meta analysis. Epidemiol. Rev., 29: 115-28. DOI: 10.1093/epirev/mxm008 